\title{
Comparison of weight, depth, and diagnostic adequacy of specimens obtained with 16 different biopsy forceps designed for upper gastrointestinal endoscopy
}

\author{
B J Z DANESH, M BURKE, J NEWMAN, A AYLOTT, \\ P WHITFIELD, AND P B COTTON \\ From the Department of Gastroenterology, The Middlesex Hospital, London, Bland Sutton Institute of \\ Pathology, and Department of Surgical Studies, The Middlesex Hospital Medical School, London
}

SUMmaRY The influence of endoscopic forceps variables (size, design, and make) on biopsy specimen weight, depth, and diagnostic adequacy has been studied in vitro on normal human stomach, and in vivo at endoscopy in dog and in patients. Greater pressure during the biopsy procedure yielded significantly heavier, deeper, and histologically more acceptable specimens. Standard sized forceps (diameter $2.4 \mathrm{~mm}$ ) and those with ellipsoid cups consistently produced larger specimens than the smaller 'paediatric' forceps $(1.8 \mathrm{~mm})$ and those with round cups. Deeper specimens were also obtained using the standard forceps. In vitro and in vivo in the dog, the standard sized forceps also produced specimens of greater diagnostic adequacy than the paediatric forceps. At endoscopy in patients, however, we could not detect any influence of the size, shape, and presence of forceps spike or fenestration on the diagnostic adequacy of the specimens.

Gastrointestinal endoscopy is now used routinely in most general hospitals, and endoscopic biopsy specimens constitute a significant proportion of the material handled by routine histopathology laboratories. Most instruments for upper gastrointestinal endoscopy have biopsy channels which permit the use of forceps $2.4 \mathrm{~mm}$ in diameter. The specimens are of necessity small, and concern has been expressed about their adequacy. Such concern has been highlighted by the use of even smaller 'paediatric' fibrescopes, some of which have a channel which permits the use of forceps, only 1.8 $\mathrm{mm}$ in diameter. Apart from their size, endoscopic biopsy forceps vary in their precise design; the endoscopist is faced with a bewildering variety.

Two small studies have addressed part of the problem - the size of the forceps. Siegel and colleagues $^{1}$ showed that forceps with $4 \mathrm{~mm}$ bite size yielded larger specimens than 3 and $2.5 \mathrm{~mm}$ forceps; Neuhaus and Hintze ${ }^{2}$ showed that $2 \mathrm{~mm}$ forceps provided specimens inferior to those obtained with experimental $3.5 \mathrm{~mm}$ and $5 \mathrm{~mm}$ forceps.

We have compared the weight (as a measure of

Address for correspondence: Dr P B Cotton, FRCP. Department of Gastroenterology. Middlesex Hospital. Mortimer Street, London W1N 8AA. Reccived for publication 9 May 1984 size), depth, quality, and diagnostic adequacy of biopsy specimens obtained by each of 16 commercially available forceps for upper gastrointestinal endoscopy, of different size, shape, design, and make. Comparisons were made in three circumstances: (a) in vitro on resected normal human stomach, (b) at endoscopy in a dog, and (c) at diagnostic endoscopy in man. We also studied the effect of pressure at time of biopsy.

\section{Methods}

FORCEPS

Sixteen forceps of different diameter $(1.8 \mathrm{~mm}, 2.4$ $\mathrm{mm}$, and $3.4 \mathrm{~mm}$ ), shape (round, ellipsoid, alligator), design (ordinary, spiked, fenestrated), and make (Fujinon, Olympus, ACMI) were used (Table 1).

\section{BIOPSY STUDIES}

In vitro study on normal human stomach

Portions of two stomachs removed during pancreato-duodenectomy were cut into squares $(6 \times 6 \mathrm{~cm})$ and kept moist in normal saline. Each portion was pinned out on a flat piece of cork with a hole $5 \mathrm{~cm}$ diameter in its centre, which in turn was 
Table 1 Details of forceps used and weight of gastric biopsy specimens obtained at heavy pressure (14 specimens with each forceps) in vitro

\begin{tabular}{|c|c|c|c|c|c|c|}
\hline No & Make & Code & Design & Shape & Size & $\begin{array}{l}\text { Biopsy weight }(\mathrm{mg}) \\
\text { mean } \pm S D\end{array}$ \\
\hline 1 & Fujinon & K181650R & $\mathrm{O}$ & Round & $1.8 \mathrm{~mm}(5 \mathrm{Fr})$ & $3 \cdot 21 \pm 0 \cdot 33$ \\
\hline 2 & Fujinon & $\mathrm{K} 181650 \mathrm{H}$ & $\mathbf{S}$ & Round & & $2.94 \pm 0.44$ \\
\hline 3 & Olympus & FB1K & $\mathrm{O}$ & Round & & $3 \cdot 26 \pm 0 \cdot 40$ \\
\hline 4 & ACMI & 9116 & $\mathbf{F}$ & Round & & $2.94 \pm 0.49$ \\
\hline 5 & Fujinon & K181600R & $\mathrm{O}$ & Ellipsoid & & $4 \cdot 03 \pm 0 \cdot 70$ \\
\hline 6 & Olympus & FB14K & $\mathrm{O}$ & Ellipsoid & & $4.84 \pm 0.73$ \\
\hline 7 & Olympus & & $\mathbf{S}$ & Ellipsoid & & $4 \cdot 71 \pm 1 \cdot 14$ \\
\hline 8 & Olympus & FB21K & $\mathbf{F}$ & Ellipsoid & & $5 \cdot 44 \pm 0 \cdot 56$ \\
\hline 9 & Olympus & FB15K & $\mathrm{O}$ & Alligator & & $5 \cdot 14 \pm 0 \cdot 50$ \\
\hline 10 & Fujinon & K241800R & $\mathrm{O}$ & Round & $2.4 \mathrm{~mm}(7 \mathrm{Fr})$ & $5 \cdot 16 \pm 0 \cdot 72$ \\
\hline 11 & Fujinon & $\mathrm{K} 241800 \mathrm{H}$ & $\mathbf{S}$ & Round & & $6 \cdot 04 \pm 0 \cdot 56$ \\
\hline 12 & Olympus & FB3K & $\mathrm{O}$ & Round & & $5 \cdot 93 \pm 0 \cdot 71$ \\
\hline 13 & Olympus & FB28U & $S / F$ & Round & & $6 \cdot 83 \pm 0 \cdot 55$ \\
\hline 14 & Olympus & FB12K & $\mathbf{S}$ & Ellipsoid & & $7 \cdot 69 \pm 0 \cdot 78$ \\
\hline 15 & ACMI & $7035 \mathrm{~A}$ & $S / F$ & Ellipsoid & & $9 \cdot 33 \pm 1 \cdot 55$ \\
\hline 16 & Olympus & FB13K & $\mathbf{S}$ & Round & $3.4 \mathrm{~mm}(9 \mathrm{Fr})$ & $15 \cdot 51 \pm 2.09$ \\
\hline
\end{tabular}

$\mathrm{O}=$ ordinary, $\mathrm{S}=$ spiked, $\mathrm{F}=$ fenestrated, $\mathrm{Fr}=$ French gauge.

placed on a digital weighing balance (accuracy $\pm 0.01 \mathrm{~g}$ ). The amount of pressure applied during the biopsy procedure was recorded as a change in weight. The biopsy forceps was steadied through the shaft of a pin-chuck, simulating the shaft of an endoscope.

Biopsy specimens were taken by each of the 16 forceps at two different pressures - light pressure (recorded at $15 \mathrm{~g}$ weight) when the forceps rested gently on the suspended mucosa, and heavy pressure (recorded as $75 \mathrm{~g}$ ) when sufficient pressure was applied to produce a bend in the forceps shaft which had been fixed $6 \mathrm{~cm}$ from the tip of the pin-chuck.

Fourteen specimens were taken in random order from each stomach using each forceps, and applying both light and heavy pressure. A total of 448 biopsy specimens were taken and weighed; 14 specimens were lost in transit and 71 specimens were damaged during weighing and fragmented due to autolysis, and these occurred at random amongst all the forceps and at both pressures. The remaining 363 specimens were assessed histologically.

In vivo endoscopy in dog stomach

Endoscopy was performed on an anaesthetised dog, using an instrument with a biopsy channel $2.8 \mathrm{~mm}$ in diameter, thus precluding the use of the largest 3.4 $\mathrm{mm}$ forceps. The other 15 types of forceps were each used to take four gastric biopsies, two at light pressure and two at heavy pressure; 60 specimens were obtained, of which 57 were examined histologically, three specimens being damaged at random during weighing (unrelated to the type of forceps).

\section{Endoscopic biopsies on patients}

Eleven different forceps were used during diagnostic endoscopy in 29 patients. Because multiple biopsies with the simultaneous use of all these forceps on individual patients is not feasible, a study based on a Balanced Incomplete Block design was used. Each consecutive patient was randomly allocated to a specific study group of four patients, in which four different forceps compared two variables. Using one of four balanced combinations of three forceps, 12 biopsies (four with each forceps) were taken at heavy pressure from each patient; thus 12 biopsies were obtained by each forceps from three different patients. Altogether, 288 biopsies were taken from 24 patients in six such study groups; 265 biopsies were examined histologically as 23 specimens were damaged during weighing (randomly distributed amongst the patients and forceps). Five further patients in a similar study group had 60 oesophageal biopsies taken, of which 57 were examined histologically; three biopsies (unrelated to any particular patient or forceps) were unsatisfactory and fragmented during processing.

\section{WEIGHING OF SPECIMENS}

All biopsy specimens were orientated on fibre-free cards and weighed on a digital balance (accuracy $\pm 0.01 \mathrm{mg}$ ).

PROCESSING AND HISTOLOGICAL ASSESSMENT Specimens were fixed in $10 \%$ formol saline. After wax impregnation, each biopsy was embedded on edge along its longitudinal axis using heated forceps, in wax moulds. Each set of specimens was 
embedded in parallel lines for convenience of sectioning and histological examination. Sections were taken at two levels: a $4 \mu$ section was taken after the tissue blocks had been trimmed and all samples represented, followed by a further section $60 \mu$ deeper. All were stained with haematoxylin and eosin. They were independently examined using light microscopy by two pathologists who had no prior knowledge of the type of forceps used in each set of biopsies. Specimens were assessed for depth (presence or absence of deep mucosa and muscularis mucosae), quality (specimen preservation with minimal fragmentation and tissue artefact) and for diagnostic adequacy, defined by us as a well orientated specimen of sufficient depth and quality to permit full histological assessment and diagnostic conclusion.

\section{STATISTICAL ANALYSIS}

In all studies the forceps were divided into groups of four to allow for the number of variables (size, shape, design, and make) under study. Each group represented a study model and compared two of the forceps variables only. To examine the simultaneous influence of each forceps variable and that of pressure on specimen weight, Cross-Classified analysis of variance ${ }^{3}$ was applied to each study model in the in vitro and dog studies. In the patients study, where the specimens were obtained from different stomachs, and assessment of both forceps and tissue variation was necessary, the Balanced Incomplete Block Analysis of Variance ${ }^{3}$ was used. This analysis gives a balanced assessment of forceps and tissue variation by comparing similar numbers of biopsies, using similar number of forceps on similar number of patients, within a study group. The $\chi^{2}$ test and, where applicable, Fisher's Exact test were used in all the studies to compare the frequency of histological features of the specimens examined. A probability value of less than 0.05 was considered significant.

\section{Results}

SPECIMEN SIZE

Table 1 shows the weight of specimens obtained with each pair of biopsy forceps in vitro, using heavy pressure; the overall size of the forceps was the most important determining factor. Figure 1 shows the results of detailed comparisons in the three study groups from which it is clear that heavy pressure, larger forceps and ellipsoid cups, significantly increased the weight of the specimens obtained whereas the make of forceps, and the presence of fenestration or a spike made no consistent difference. Specimen weight was not influenced by sampling variation between patients.

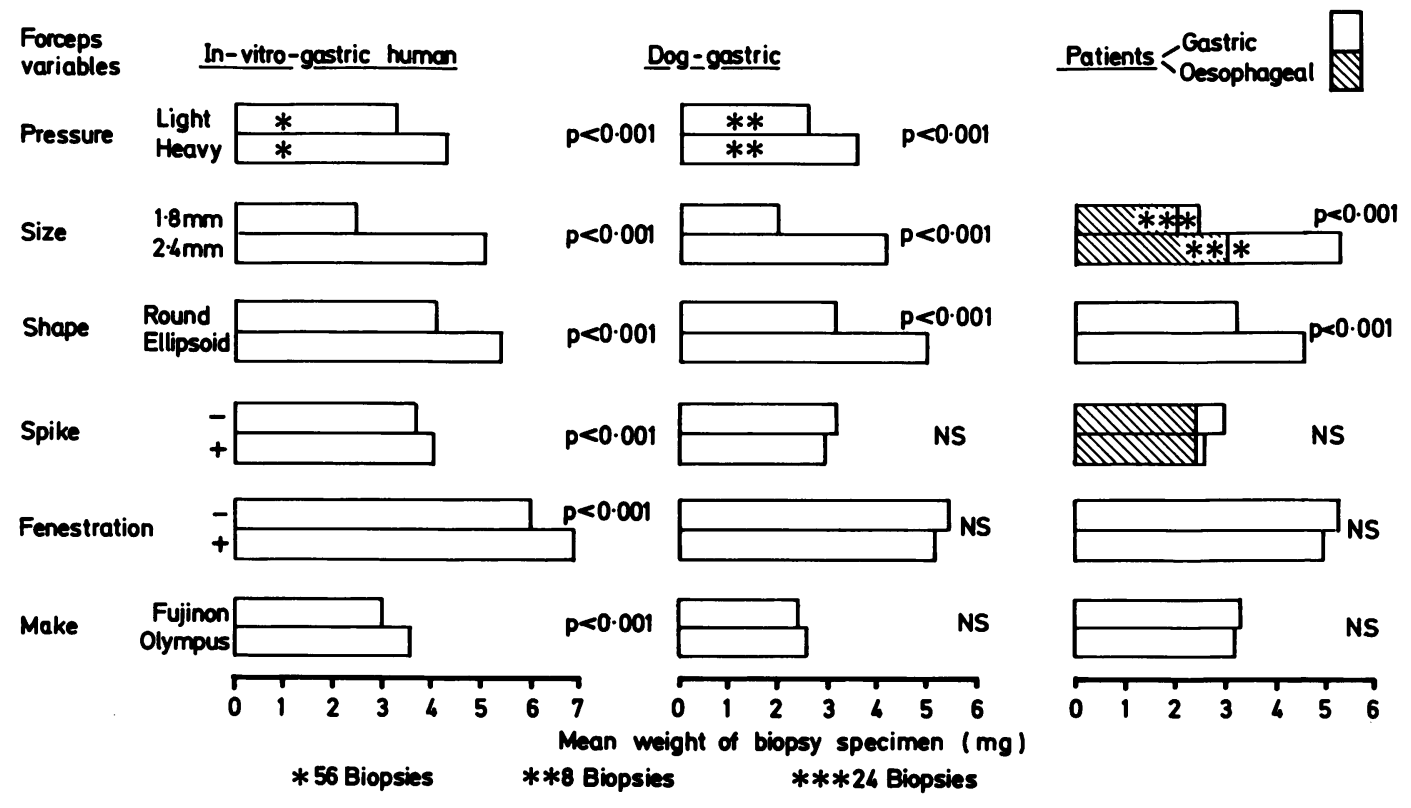

Fig. 1 Mean weights of biopsy specimens taken during in vitro and in vivo studies, with significance of differences by forceps characteristic, and pressure. (NS = not significant). 
SPECIMEN DEPTH

Deeper specimens were obtained using the standard forceps and by applying heavy pressure (Table 2).

DIAGNOSTIC ADEQUACY

A significantly higher proportion of diagnostically adequate specimens were obtained using the standard forceps and applying heavy pressure as opposed to the use of the paediatric forceps and applying low pressure both in vitro, and at endoscopy in dog (Fig. 2). The adequacy of the specimens obtained at endoscopy in the human stomach and oesophagus was not influenced by the size of the forceps, their shape or make, or by the presence or absence of a spike or fenestration (Fig. 2). The histological diagnoses included oesophagitis, gastritis, with and without intestinal metaplasia, gastric dysplasia, and carcinoma.

\section{Discussion}

These studies were initiated in an attempt to provide guidance for biopsy procedures. One practical message is that the specimen size and depth were
Table 2 Influence of biopsy forceps size and pressure on depth of specimens

\begin{tabular}{|c|c|c|c|}
\hline \multirow[b]{3}{*}{$\begin{array}{l}\text { Variable } \\
\text { compared }\end{array}$} & \multicolumn{3}{|c|}{ Features present in specimens } \\
\hline & \multicolumn{2}{|c|}{ Muscularis Mucosae } & \multirow{2}{*}{$\begin{array}{l}\text { Deep mucosa } \\
\text { Dog } \\
\% \text { (no/total) }\end{array}$} \\
\hline & $\begin{array}{l}\text { In vitro } \\
\% \text { (no/total) }\end{array}$ & $\begin{array}{l}\text { Patients } \\
\%(\text { no/total })\end{array}$ & \\
\hline $1.8 \mathrm{~mm}$ & $14 \%(9 / 64)$ & $37 \%(27 / 73)$ & $67 \%(10 / 15)$ \\
\hline $2.4 \mathrm{~mm}$ & $\begin{array}{l}41 \%(32 / 79) \\
\mathrm{p}<0 \cdot 001\end{array}$ & $\begin{array}{l}63 \%(40 / 63) \\
\mathrm{p}<0 \cdot 01\end{array}$ & $\begin{array}{l}94 \%(15 / 16) \\
\text { NS }\end{array}$ \\
\hline Light & $16 \%(29 / 178)$ & - & $52 \%(15 / 29)$ \\
\hline Heavy & $\begin{array}{l}31 \%(58 / 185) \\
\mathrm{p}<0.01\end{array}$ & - & $\begin{array}{c}100 \%(28 / 28) \\
\mathrm{p}<0 \cdot(0) 1\end{array}$ \\
\hline
\end{tabular}

NS $=$ not significant

dependent on the pressure applied to the forceps during the biopsy procedure. Specimens taken with the standard $(2.4 \mathrm{~mm})$ forceps were significantly larger and deeper than those taken with the 'paediatric' $(1.8 \mathrm{~mm})$ forceps. Forceps with ellipsoid-shaped cups also yielded larger specimens than those with round cups. The size of the

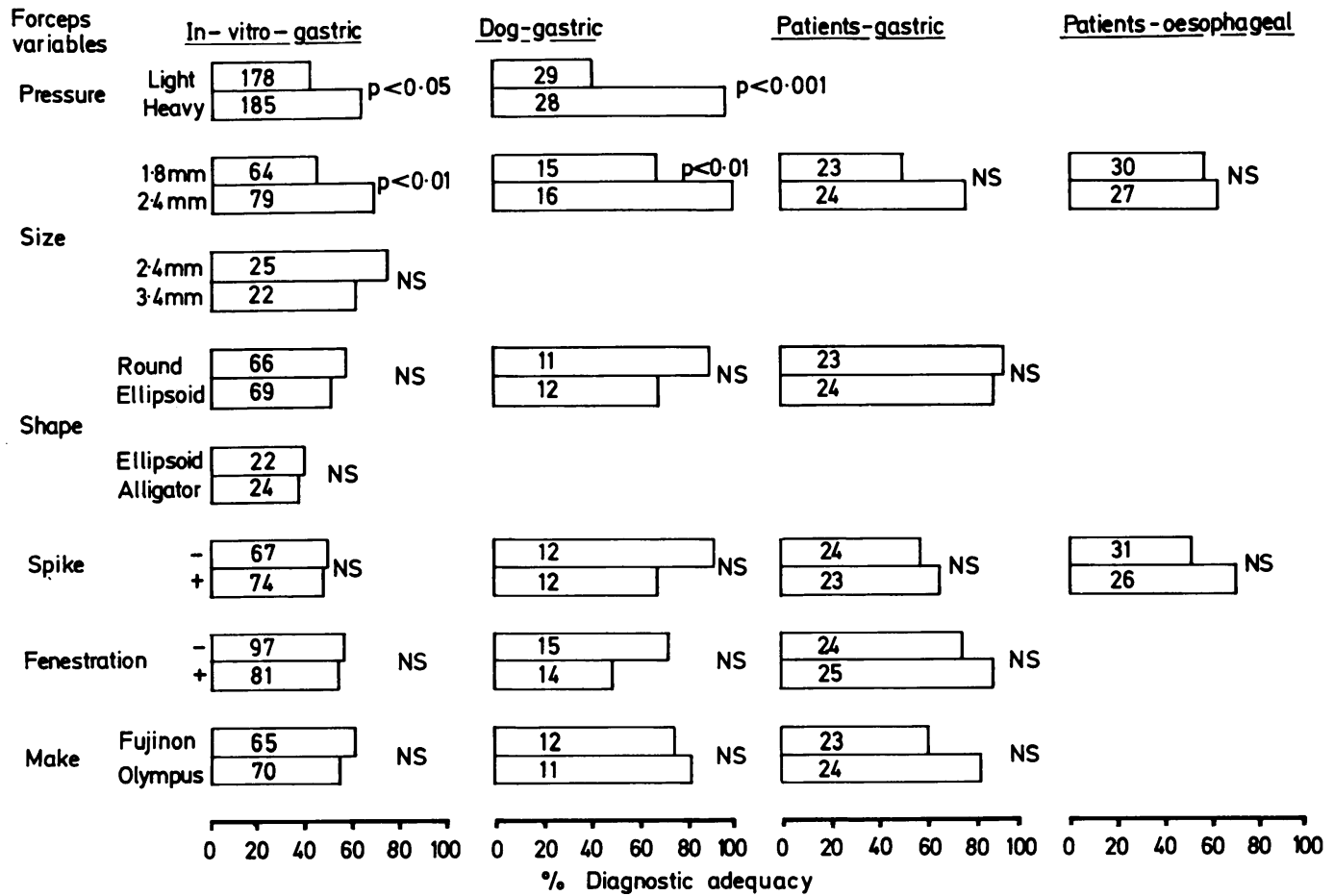

Fig. 2 Diagnostic adequacy (\%) of groups of specimens obtained under different conditions within the experiments, with statistical significance $(N S=$ not significant). Numbers within blocks indicate total number of specimens compared, for each forceps variable, in each study. 
specimen was not influenced to any great extent by fenestration of the cup, by the presence or absence of a central spike or by make.

The overall diagnostic adequacy of individual biopsy specimens depended on the pressure applied by the forceps, and on the size of the specimens; smaller specimens being less adequate for diagnostic interpretation than larger specimens both in the in vivo study and at endoscopy in the dog, where optimum conditions prevailed. Such differences were, however, not apparent in material obtained in patients perhaps owing to difficulty in pinpointing the lesion together with other factors such as the nature of the disease and the presence of associated bleeding, ulceration, necrosis, or fibrosis. The quality of the tissue obtained under such circumstances and its handling both at the time of biopsy and subsequently in the laboratory were important in determining adequacy. Smaller specimens tended to fragment more easily and were technically more difficult to orientate correctly, so that even though multiple sections were taken, the tissue did not prove adequate. Because of the small number of patients in our study, we were unable to assess fully the part such variables played in determining the diagnostic adequacy of the tissue obtained.

Concern about the size of biopsy specimens has led to the development of even larger forceps in an effort to improve diagnostic adequacy; of these only forceps $3.4 \mathrm{~mm}$ in diameter are available commercially in this country for use with endoscopes having a larger channel. They are not used often in routine clinical practice. When we tested them in vitro, such forceps yielded specimens larger but no more adequate than those obtained using the standard forceps. This is in agreement with the findings of Siegel et al ${ }^{1}$ at endoscopy in 34 patients. They found that although forceps with bite size $4 \mathrm{~mm}$ produced larger specimens than those with bite size 3.0 and $2.5 \mathrm{~mm}$, there was no significant difference in the adequacy of the specimens obtained. Like us, Neuhaus and Hintze ${ }^{2}$ showed that their large: forceps ( 3.5 and $5 \mathrm{~mm}$ diameter) produced deeper specimens than $2 \mathrm{~mm}$ forceps. Their experimental (5 $\mathrm{mm}$ ) forceps may have application in the diagnosis of submucosal lesions, such as lymphomas. There are, however, other methods of obtaining submucosal tissue - for example, endoscopic needle aspiration, snare loop biopsy and the use of muzzleloading biopsy capsules and jumbo-jaw forceps. ${ }^{4}$

This study has only asessed diagnostic adequacy which differs from diagnostic accuracy, especially in the situation which concerns most clinicians - that is, the detection or exclusion of malignancy. In their study, Siegel et al ${ }^{1}$ showed that although larger forceps yielded to some extent better specimens the overall diagnostic accuracy of each forceps did not differ signifiantly. Both they and other workers ${ }^{5-7}$ have emphasised the importance of taking multiple biopsies when a malignant lesion is suspected, a view which we endorse.

We have shown that under closely controlled conditions the precise shape, design, and make of the forceps used are not of practical importance, but that bigger, deeper, and more adequate specimens are obtained by using the standard sized forceps and by applying pressure at the time of biopsy. As, however, the quality of the tissue may depend on the sampling conditions at the time of biopsy, multiple biopsies must be taken to ensure provision of material adequate for diagnostic assessment.

We wish to thank Dr F Nashat for help with the dog experiment, Mr R C G Russell for providing surgical specimens, and colleagues in the Department of Surgical Studies and Clinical Measurement. We are also grateful to ACM, Pyser and KeyMed for the loan of biopsy forceps and to Mr D McLaren, Department of Mathematics, Glasgow University for statistical advice.

\section{References}

1 Siegel MS, Barkin JS, Rogers AI, Clark R. Gastric biopsy: a comparison of biopsy forceps. Gastrointest Endosc 1983; 29: 35-6.

2 Neuhaus B, Hintze R. A comparative study in the evaluation of $5 \mathrm{~mm}$ forceps biopsy to $2 \mathrm{~mm}$ and $3.5 \mathrm{~mm}$ forceps biopsy. Acta Endoscopica 1979; 9: 95-9.

3 Moore PG, Shirley EA, Edwards DE. Standard statistical calculations. London: Pittman, 1972: 39.

4 Cotton PB. Muzzle-loaded jumbo biopsy at gastroscopy. Acta Endoscopica 1983; 13: 71-3.

5 Dekker W, Tytgat GN. Diagnostic accuracy of fiberendoscopy in the detection of upper intestinal malignancy; a follow-up analysis. Gastroenterology 1977; 73: $710-4$.

6 Misumi A, Mori K, Ikeda $\mathrm{T}$ et al. Evaluation of fibregastroscopic biopsy in the diagnosis of gastric cancer; a study of 339 cases. Gastroenterol Jpn 1978; 13: $255-63$.

7 Graham DY, Schwartz JT, Cain GD, Gyorkey F. Prospective evaluation of biopsy number in the diagnosis of esophageal and gastric carcinoma. Gastroenterology 1982; 82: 228-31. 